\title{
مؤتمر فقه الانتماء إلى البجتمع والأمّة
}

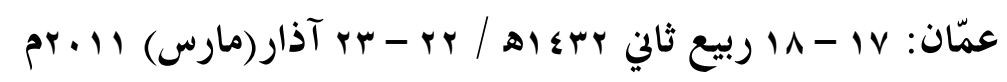

\section{مكتب الأردن}

نظم المعهد العالمي للفكر الإسلامي/ مكتب الأردن، والجامعة الأردنيـة، مـــؤتمراً

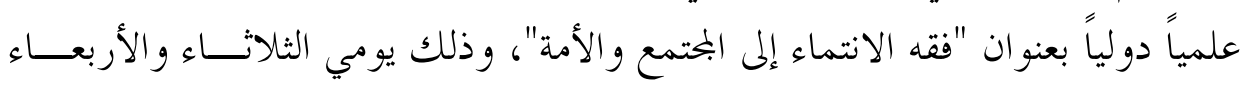

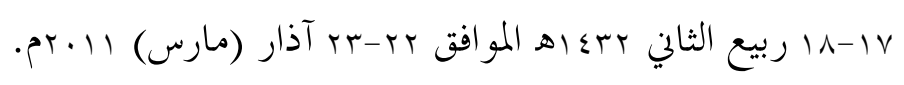

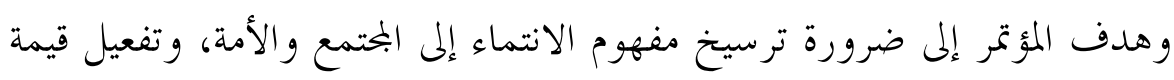

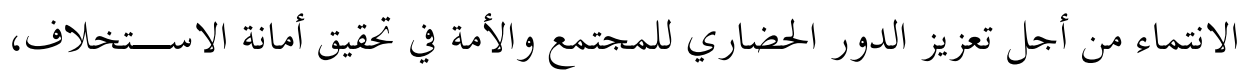

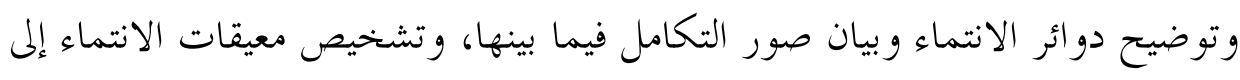

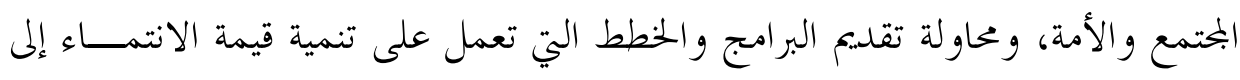
البجتمع والأمة.

وشارك في المؤتمر ثمانية عشر باحثاً، يمثلون خمـسـ دول هـــي: الأردن والجزائسر

$$
\text { وسوريا والمغرب ومصر. }
$$

وقد تحدث في الجلسة الافتتاحية الدكتور رائد عكاشة المستشار الأكاديمي للمعهد

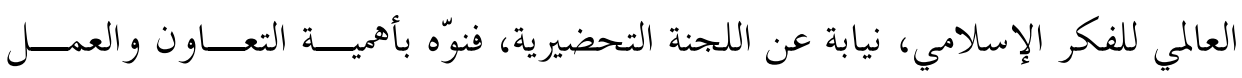

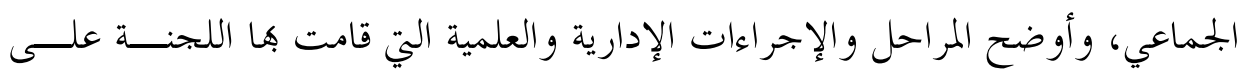

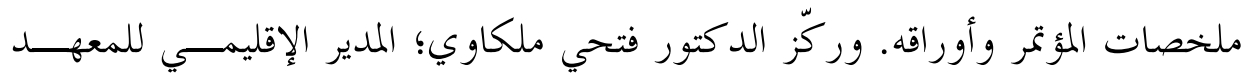

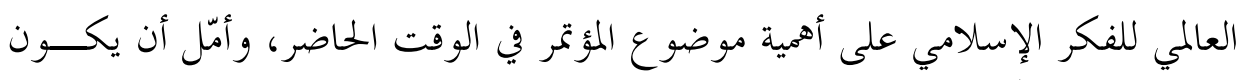

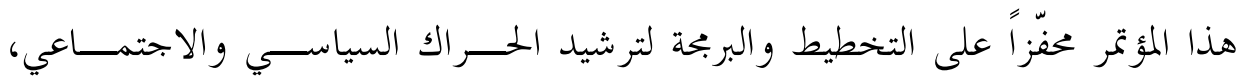

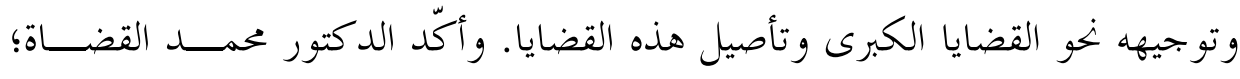

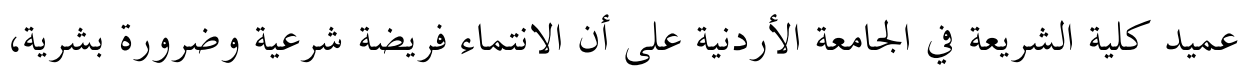

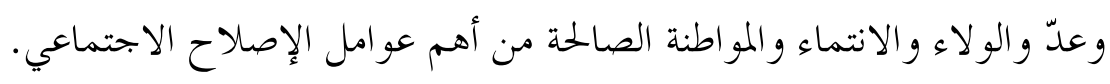


وتواصلت أعمال اليوم الأول (الثلاثاء r آذار) في ثلاث جلسات عمل؛ إذ ترأس

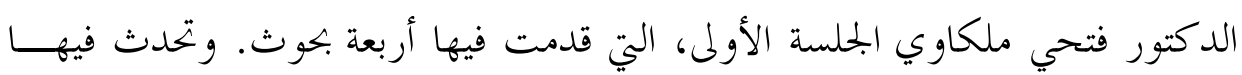

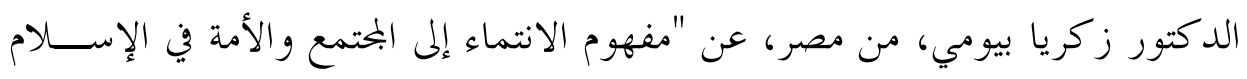

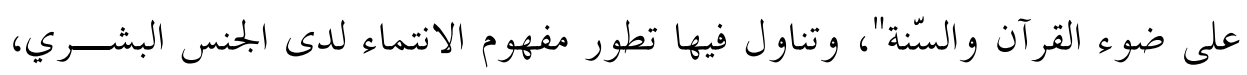
وركزّ على ضرورة الانتماء العقدي بوصفه جزءاً من الإيمان بالرسالة الإسلامية.

وتناول الدكتور إسماعيل الحسين، من المغرب، "مقاربات ومسائل من فقه الانتماء

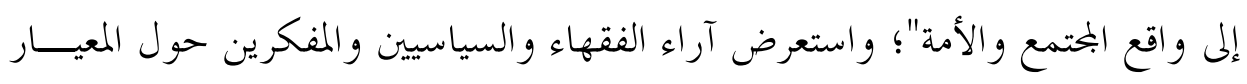

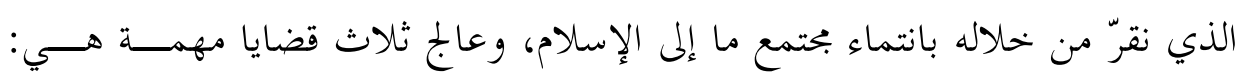
علاقة الانتماء بوحدة الأمة، وعلاقته بالاستبداد والحرية، وعلاقته بواقع التجنّس. وجاء بحث الدكتور الحاج دواق، من الجزائر، عن "الانتماء إلى الأمة في الرؤيسـة

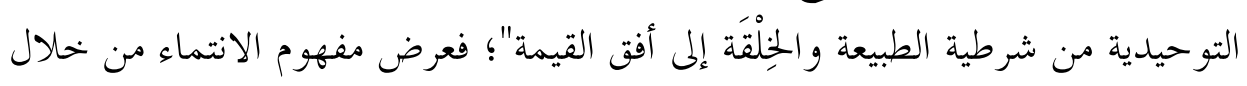

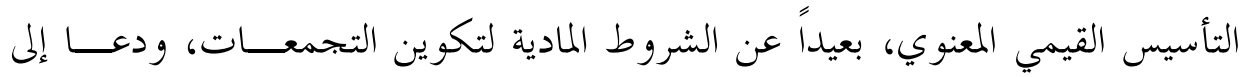

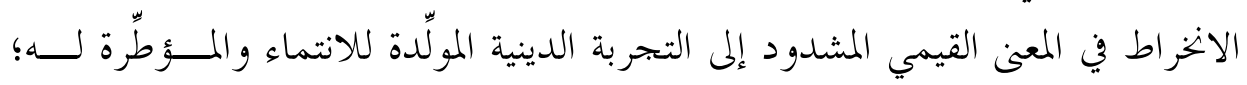
ضماناً لنجاحه.

وانتهت الجلسة بورقة الدكتور سفير الجراد، من سوريا، المعنونة بــ: "الهوية بين ضرورات الذات و تطورات العصر". فبيّن المنهج الفكري والعملي لتأصيل فقه الانتماء

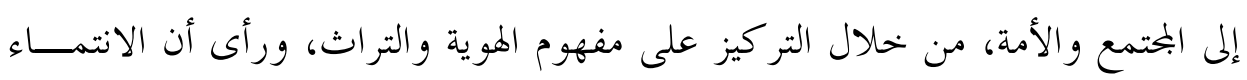

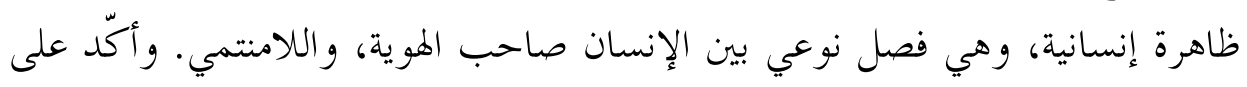
ارتباط الانتماء بالشعور بالكرامة الإنسانية والحرية.

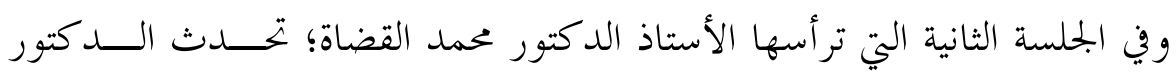

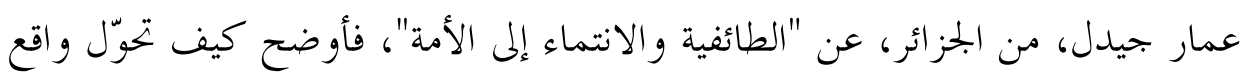

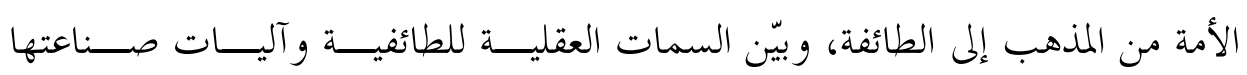

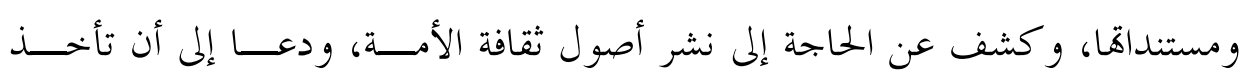


القيادات الفكرية والسياسية دورها الحقيقي في التحرر من الواقع، الذي يحرص علــى التجزئة و الفرقة.

وكشف الدكتور صالح نعمان، من الجزائر، عن "دور العقيدة الإسلامية في تحقيق

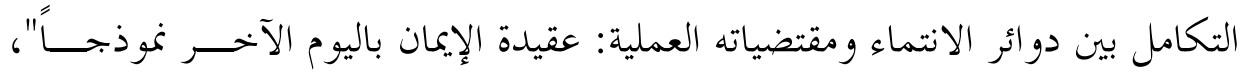

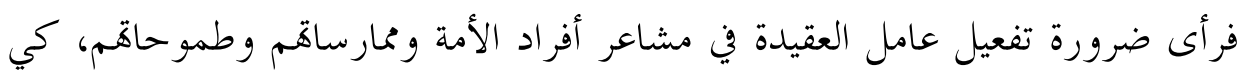

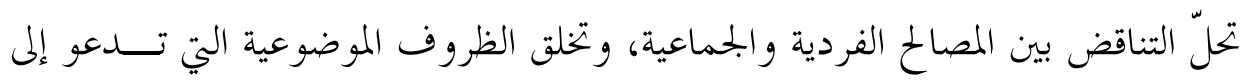
تحرّك الإنسان وفق مصالح الجماعة.

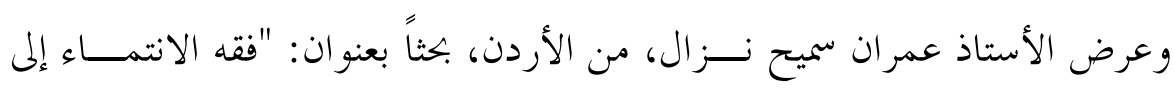

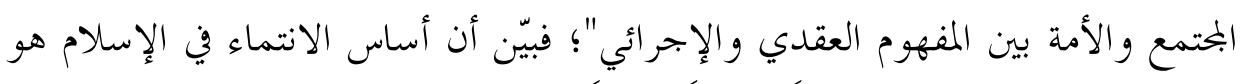

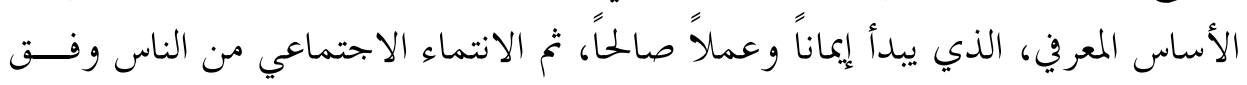

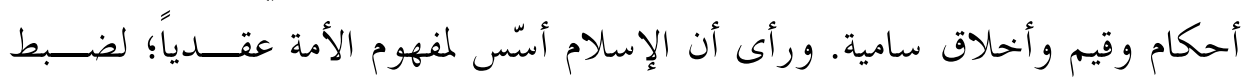

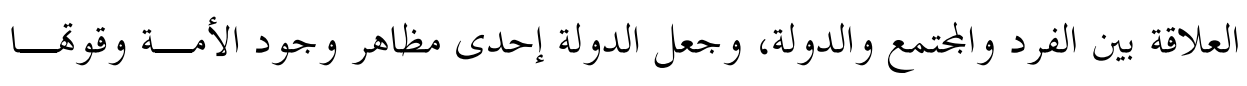
وعزها.

وعقدت في الوقت نفسه جلسة موازية باللغة الإبحليزية، ترأسها الدكتور عــــنان

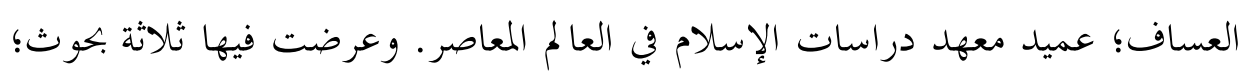

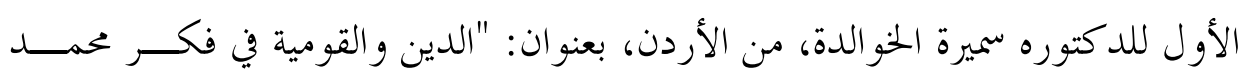

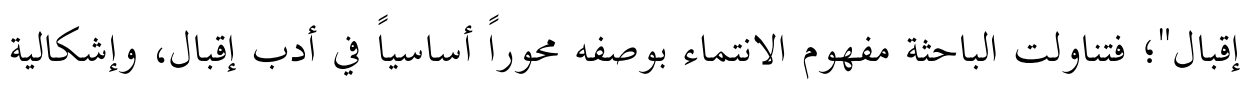

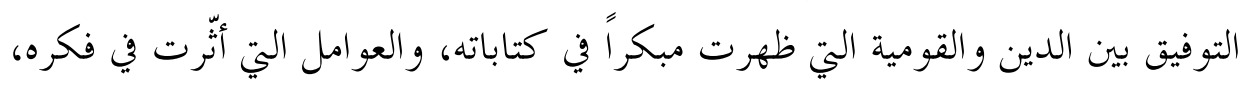

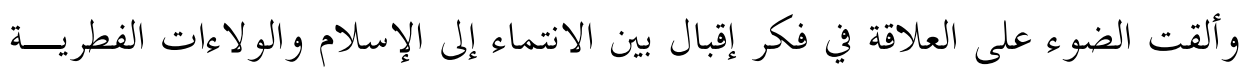
الأخرى . (الأعت.

ووجاء بحث الدكتوره دعاء فينو، من الأردن، بعنوان: "معوقات عملية الانتمــاء؛

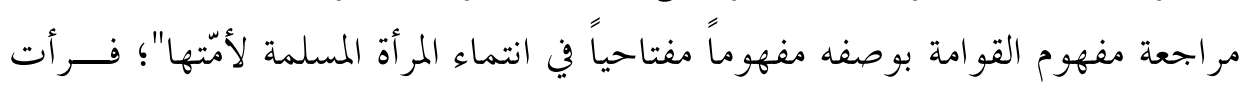

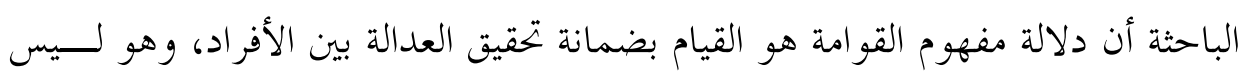

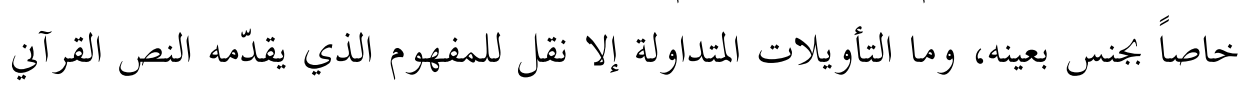




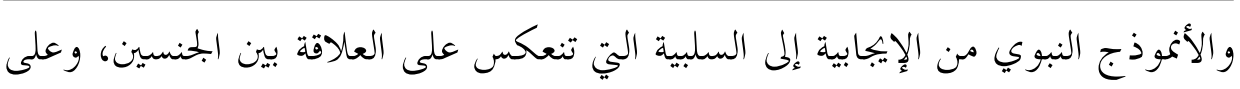
انتماء المرأة المسلمة إلى أمّتها.

وتحدث الدكتور علاء الدين عدوي، من الأردن، عن "الهدي القرآني والنبوي في

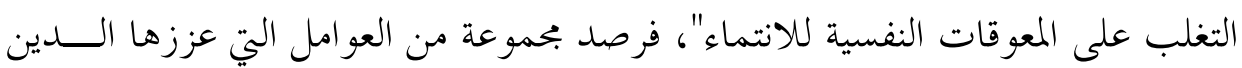

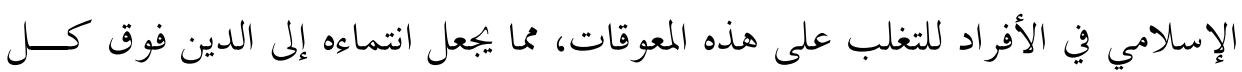

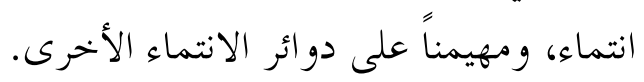

قد بدأت جلسات اليوم الثاني (الأربعاء rr آذار) بجلسة ترأسها الأستاذ الـــــــور

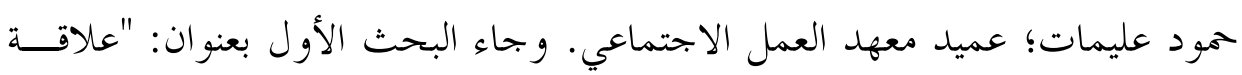

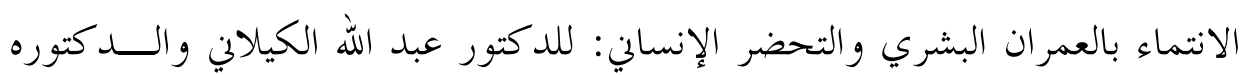

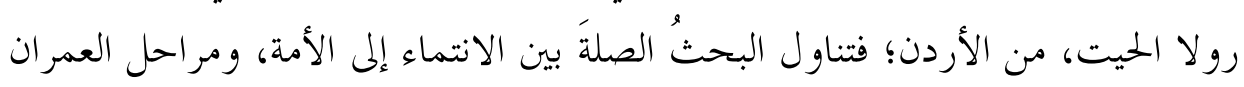

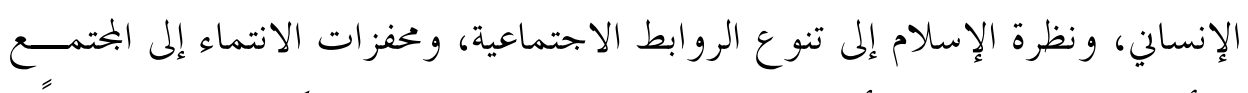

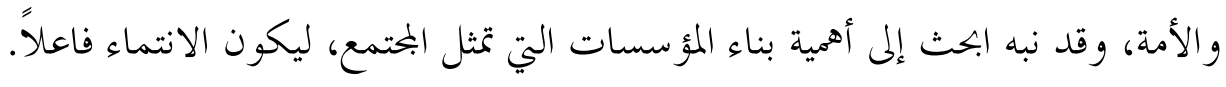
وتحدث الدكتور عبد القادر عبد العالي، من الجزائر، عن "أزمة الانتماء على ضوء

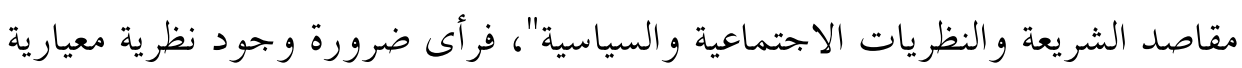

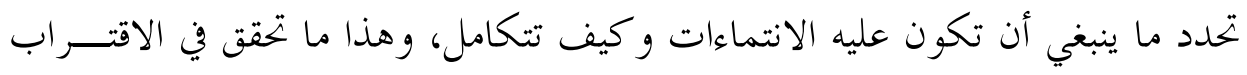

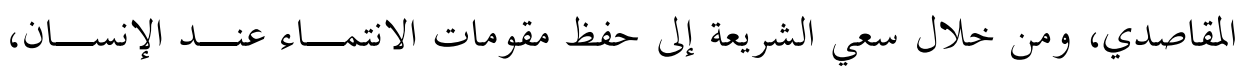

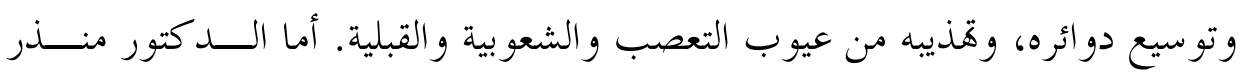
زيتون، من الأردن، فجاء بحثه "عن الحرمان من حقوق وتون المو اطنة أو الانتقاص منها وأثره

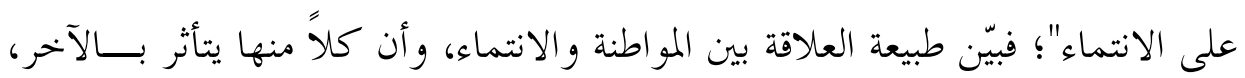

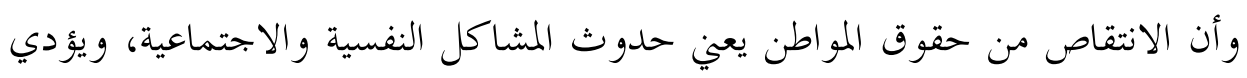
إلى إنتاج الفرد اللامنتمي.

وختمت الجلسة ببحث للأستاذ إبراهيم غرايبة، من الأردن، عن "قيم الانتماء عند أهل الحرف والمهن و الوظائف العامة". وقد حاول البحث أن يستوعب قيم الانتماء في

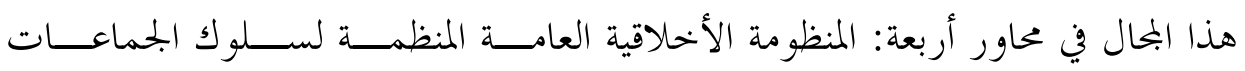


و المجتمعات العربية والإسلامية وقيمها في الانتماء، و المنظومة الثقافية العامة للمجتمعات

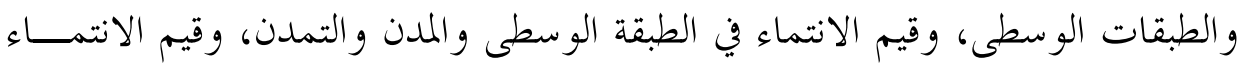

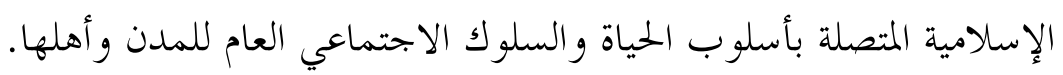

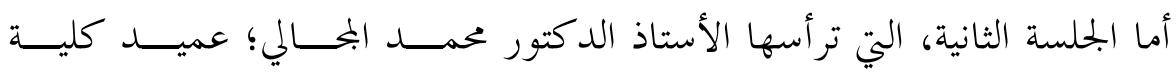
الدراسات العليا في الجامعة الأردنية، فعرضت فيها ثلاثة بحوث، أولها للدكتور حسان

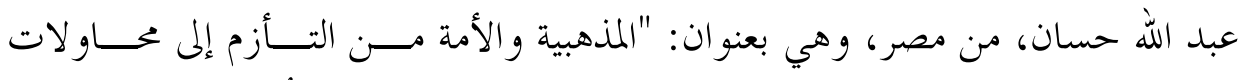

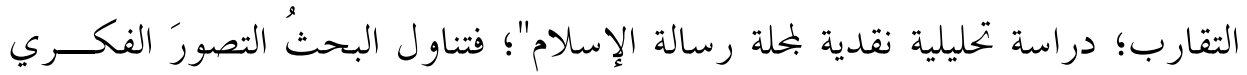

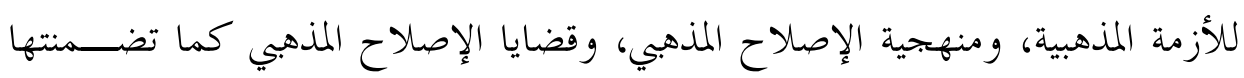

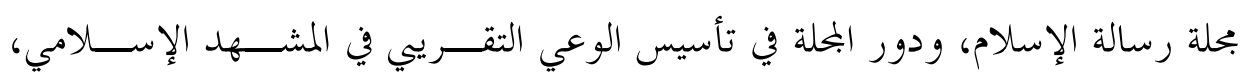
وختمت بنظرة نقدية للمضامين التقريبية للمجلة.

وعرض الدكتور إحسان سمارة، من الأردن، بحثاً بعنوان: "مفهوم الأمة الإسلامية ومقوماها في هدي المصطفى صلى الله عليه وسلم"، ناقش فيه مفهوم الأمة الإسلامية، من خلال تحليل بنود وثيقة المدينة، وجرى التركيز على بيان الفرق بين الرابطة الأمّتية

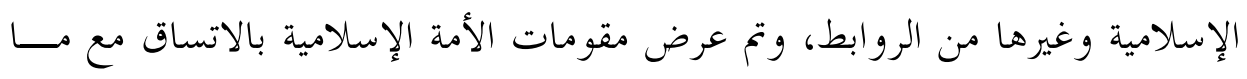

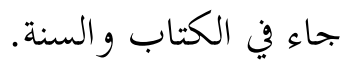

وختمت الجلسة بورقة للأستاذة شفاء الفقيه، من الأردن، بعنوان: "قاعدة الأمــــر بالمعروف والنهي عن المنكر ودورها في تعميق مفاهيم الانتماء إلى المحتمــع و الأمــة".

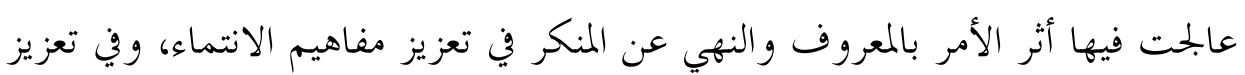

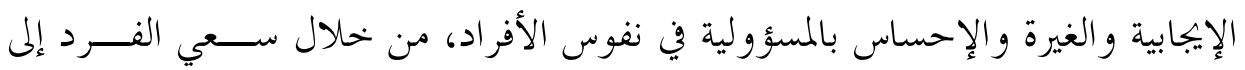
إصلاح بحتمعه.

واختتم المؤتمر أعماله بجلسة ختامية تضمنت كلمة المعهد، و كلمة الجامعة، و كلمة المشار كين، وتحدث نيابة عنهم الأستاذ الدكتور زكريا سليمان بيومي. تم تلا الدكتور

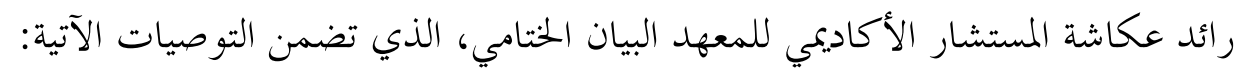


ا ـ دعوة المؤسسات الأكاديمية و البحثية ومؤسسات المحتمع المدلي، إلى نشر ثقافة

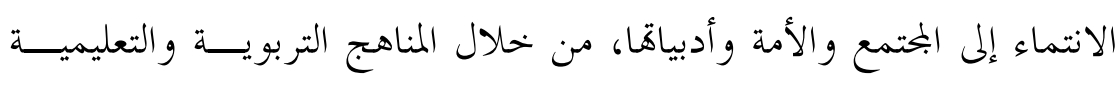

$$
\text { والبرامج الإعلامية. }
$$

r. القيام ببحوث علمية جماعية تعتمد تكامل الخبرات وتبادلها، و تعميق الجهود

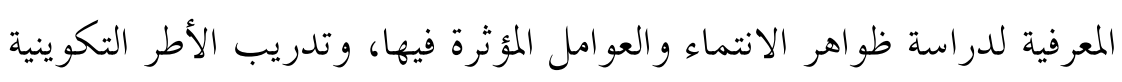
لتطوير القدرات البحثية في قضايا الانتماء إلى البحتمع والأمة.

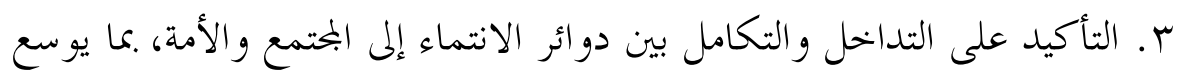

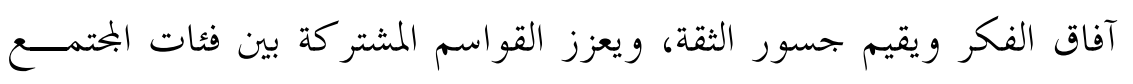
والأمة.

ـ. طباعة أعمال المؤتمر في كتاب يفيد منه طلبة العلم والمؤسســات الأكاديميـــة

و البحثية، وذلك بعد إدخال الباحثين للملاحظات الــتي أبــــاهـا المعقبـــون و والمتداخلون. 